Chapter 10

\title{
A SYSTEM DYNAMICS FRAMEWORK FOR MODELING CRITICAL INFRASTRUCTURE RESILIENCE
}

\author{
Simona Cavallini, Cristina d'Alessandro, Margherita Volpe, \\ Stefano Armenia, Camillo Carlini, Elisabeth Brein, \\ and Pierluigi Assogna
}

\begin{abstract}
In recent years, awareness of the potential consequences associated with a major disruption to the critical infrastructure has grown among public and private entities. Indeed, traditional and emerging threats endanger service continuity and, by extension, the normal functioning of modern society. This paper presents an approach for modeling the effects of critical infrastructure failures as a result of unexpected events. The transportation, energy and telecommunications infrastructures are modeled using a system dynamics approach. The work constitutes a component of the CRISADMIN Project that is focused on developing a tool to evaluate the impacts of critical events. The ultimate objective of the project is to provide decision makers with a sophisticated tool to help them mitigate negative effects in emergency situations. The prototype tool described in this paper leverages case studies of terrorist attacks and floods that have occurred in Europe.
\end{abstract}

Keywords: Interdependencies, critical events, domino effects, system dynamics

\section{Introduction}

Critical infrastructures are the backbone of modern society, enabling the vital functionalities that support economic and social interactions. The European Commission's 2008/114/EC Directive [5] defines critical infrastructure as "an asset, system or part thereof located in Member States which is essential for the maintenance of vital societal functions, health, safety, security, economic or social well-being of people, and the disruption or destruction of which would have a significant impact in a Member State as a result of the failure to maintain those functions." It is important to note that system failures in

J. Butts and S. Shenoi (Eds.): Critical Infrastructure Protection VIII, IFIP AICT 441, pp. 141-154, 2014. (C) IFIP International Federation for Information Processing 2014 
a specific critical infrastructure sector can, due to their strategic role in the socio-economic context, produce domino effects that can potentially impact all aspects of society. Understanding the effects and strategic interconnections are essential when responding to events, setting policies and determining protective investments.

Thurlby and Warren [12] state that, in order to rank preventative measures, the economic costs and potential savings (i.e., reduced casualties and/or economic losses) must be evaluated. Thus, there is a growing need to understand the costs for society as a whole - beyond those of the initially-impacted infrastructures - to fully comprehend the magnitude of an event and make appropriate response decisions.

A number of powerful simulation tools have been developed to help understand how networks may be affected by major incidents, many of which help organizations to improve their response readiness. Nevertheless, the relationship between long-term strategic choices and the ability of infrastructure networks to withstand disruptive events are not well understood. Indeed, decision making concerning investments in critical infrastructure assets, particularly those related to network control systems and the people who manage the systems, have not been thoroughly investigated to determine the long-term implications. While it is clear that spending less on assets, systems and people will degrade a system, it is not obvious how much impact any particular choice has over an extended period of time. The primary issues that need to be addressed are:

- How long-term choices related to strategic issues make a network more resilient.

- How these choices and others can minimize service loss when disruptive events occur.

- How strategic and operational choices can minimize the time taken for a network to recover and, thus, minimize the total cumulative loss of services.

The Critical Infrastructure Simulation of Advanced Models for Interconnected Network Resilience (CRISADMIN) Project studies the effects produced by critical events in an environment in which the interdependencies among several critical infrastructure sectors are modeled using a system dynamics approach and simulated in a synthetic environment. This paper discusses the key features of the methodology. The intention is to provide insights into the activities and expected outputs of the project, providing researchers and professionals with a methodology for crisis management.

\section{CRISADMIN Approach}

The CRISADMIN Project is focused on developing a tool for evaluating the impacts of critical events on critical infrastructures. The tool is intended to serve as a decision support system that is able to test and analyze critical infrastructure interdependencies, determine the modalities through which they 
are affected by predictable and unpredictable events (e.g., terrorist attacks and natural disasters), and investigate the impacts of possible countermeasures and prevention policies.

To achieve these challenging objectives, a three step approach has been formulated:

- Theoretical Model Definition: The first step is to define the system characteristics in order to establish the investigative boundaries and key reference points. This objective is achieved through the formulation of a theoretical model that identifies variables and parameters that best represent (or approximate) the infrastructures of interest. Special attention is focused on the identification of social system variables (i.e., "soft" parameters that are particularly difficult to quantify). Through careful analysis of the literature, these variables are represented in a manner compatible with system dynamics.

- System Dynamics Model Development: Causal relations between the parameters defined in the theoretical model are identified; this facilitates the construction of a number of causal maps. The causal maps provide the foundation for the simulation model structure that is validated using real case studies.

- Data Collection: Quantitative data concerning critical infrastructure functionality is collected from a number of case studies. In addition, data related to the socio-economic framework is gathered according to its availability and reliability with reference to critical events that have occurred in Europe in recent years.

Starting with the definition of a theoretical reference framework, the goal is to design a system dynamics model that constitutes the logical base for developing the decision support system. The effort engages case studies for model development and analysis. The models are integrated within the decision support structure to produce a readily accessible and usable decision making tool.

\section{Theoretical Model}

The theoretical model defines the main factors that should be considered in an emergency situation. The goal is to enhance the preparedness and response capability of all the involved actors in order to mitigate and recover from the negative effects of a catastrophic event. The main factors are investigated in terms of mutual influences, those that reinforce and those that dampen the effects of an event. Special attention is focused on the involved actors (i.e., victims, spectators and individuals responsible for managing the emergency) [3].

As in all complex environments, the vast majority of factors in emergency situations are highly interconnected. The primary objective of the theoretical model is to identify the main dependencies that impact the evolution of an event. Territorial features, the socio-economic environment, event timing (e.g., time and duration) and actor preparedness are included in the analysis. In the 
CRISADMIN Project, the effects of a critical event are studied in the context of three critical infrastructure sectors, namely transportation (private and public), energy (electricity distribution and consumption) and telecommunications (mobile and fixed).

Data domains are grouped according to the parameters included in the model. Specifically, four data domains are considered:

- Territory: This domain includes the set of variables and parameters that describe the geographic features of the territory. Territorial characteristics are particularly relevant to natural disasters; however, they may also affect the efficiency of responses in other critical situations (e.g., high territorial diversity exerts a negative influence on the promptness of emergency transportation). In this data domain, the main elements are the territorial factors and geographical nature (e.g., extension and locality) that impact vital services and social aspects.

- Environment: This domain refers to the set of variables and parameters related to the presence and activities of human beings in the territory, such as energy-related supply chain capacity, public transportation, population density and socio-economic patterns in the affected area. In the case of human-initiated critical events, environmental parameters are essential to successful crisis response.

- Apparatus: This domain includes the set of variables and parameters related to the professionals and operators who manage the effects of catastrophic events and the subsequent recovery. Typically, the apparatus includes multiple agencies and organizations, each of which have a specific role in managing minor emergencies as well as unexpected critical events. In some countries, civil authorities coordinate the activities of all the various apparatus organizations in order to mitigate the effects of a critical event.

- Events: This domain refers to the set of variables and parameters that define "normal" conditions. The data describes the evolution of normal situations over time (in contrast, the geographical features in the territory domain are time independent). Data related to the environment and apparatus depend on the normal life-cycles and are tied to the hour of the day (e.g., work hours and commuting hours), day of the week (e.g., workday, weekend, bank holiday and special days) and month of the year (e.g., festivals and vacation periods). These dependencies, which can be more or less substantial for the different variables, are considered when modeling the evolution of a critical event from the very first moments after it occurs. After the first parameter adjustment at $t_{0}$, the evolution of an event is generally considered to be independent of the hour, day and month because of the emergency effects.

Figure 1 presents the CRISADMIN theoretical model with the four data domains. Examples of parameters related to the three critical infrastructure 


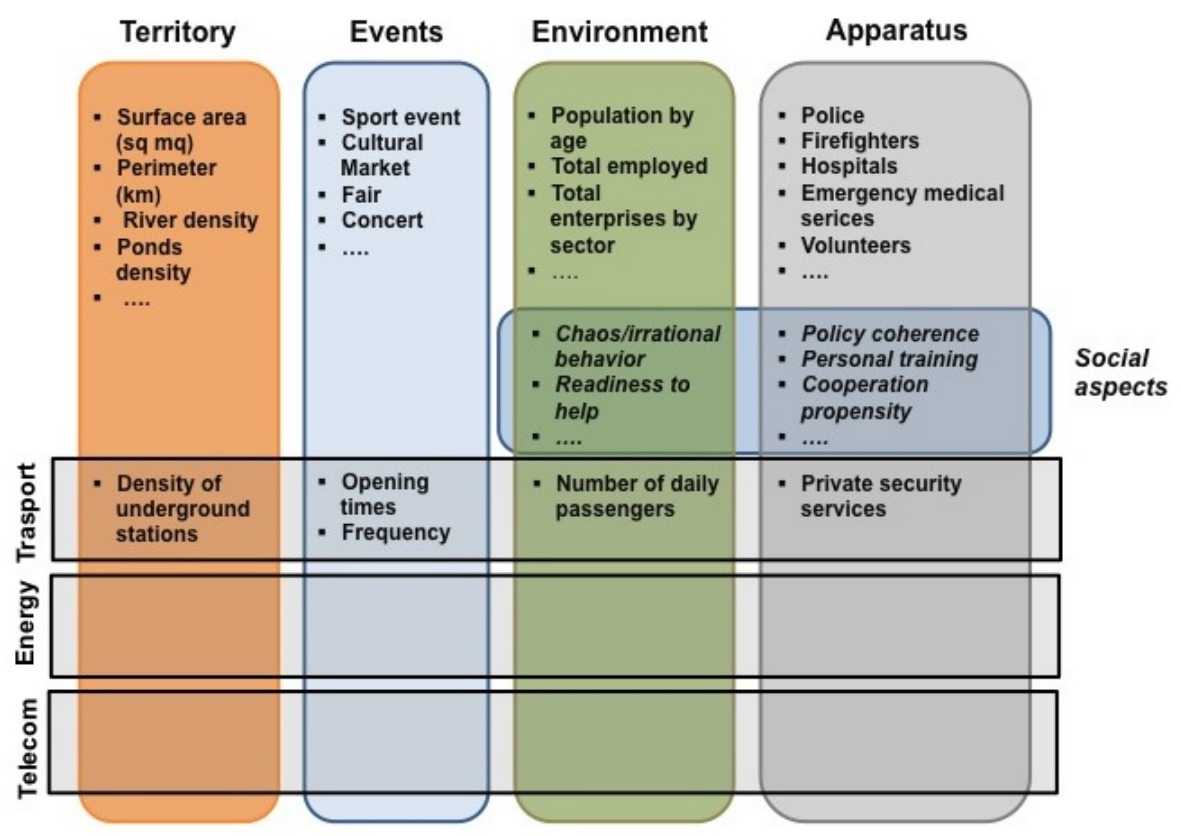

Figure 1. CRISADMIN theoretical model.

sectors are shown to illustrate the items that require investigation when responding to a critical event.

\section{Identification of Social System Variables}

The data domains capture the stage at which a critical event occurs, where countermeasures should occur and how the damage should be assessed. For this reason, social aspects involved in the preparedness and in the reaction to critical situations are included in the environment and apparatus domains. Special attention should be focused on the actors that participate in the activities being modeled and on the ordinary events that represent normal conditions.

Frequently, discussions about the effectiveness of crisis management focus on the material side (e.g., engineering and structural solutions, effective information technology and transportation networks, safeguarding electric power networks from overload and increasing the number of first responders). These discussions often ignore the thoughts, attitudes, expectations and behavior of individuals and groups who are affected by the crisis or are involved in their management. Indeed, disregarding the social and psychological aspects is problematic because each infrastructure, despite its material nature, is always embedded in the social environment. As Orlikowski and Scott [9] argue, technology is always technology in practice, highlighting the fact that the same technology will be used in very different ways depending on the social context in which 
it is used; this fact is also true in crises. Therefore, an important premise of the CRISADMIN Project is that, in order to have effective crisis management, it is of vital importance not only to understand how infrastructures and technologies work, but also to understand "how relations and boundaries between humans and technologies are not given or fixed, but enacted in practice" [9]. The realistic modeling of crises clearly requires the inclusion of social variables.

When considering the social variables to be incorporated, it is important differentiate between two categories of human actors. One category includes the people who are actively effected by the crisis. The other category comprises the individuals who attempt to manage the crisis and the subsequent recovery. A critical event induces behavioral changes in both categories of people. Note, however, that these two categories are not necessarily mutually exclusive.

The literature review undertaken by the CRISADMIN Project focused on human behavior in social systems during the response phase. Emphasis was placed on the impact on the individuals affected by the crisis as well as on the individuals involved in managing the crisis. Possible interactions, including inter-organizational coordination in emergency response, leadership in crisis situations and approaches for communication and information dissemination, were taken into account.

The literature review was by no means limited to a specific type of critical event. Indeed, the fundamental assumption was that social system variables in crisis responses are generic in nature and applicable to disparate crises. The CRISADMIN Project specifically considered papers related to crisis management from the theoretical and empirical points of view, papers related to psychological and organizational knowledge based on empirical analysis, and papers related to psychological and organizational knowledge dealing with noncrisis management and based on empirical research. The review identified a total of 34 social variables.

The literature review also yielded several general observations related to the importance of social system variables when modeling critical events:

- For effective crisis management, material needs and social needs should be considered simultaneously.

- Adequate communication is essential immediately after a crisis occurrence.

- Communication flows are core aspects of strategies for systematic crisis management.

- The need for a communication strategy has to be embraced by first responders to improve crisis management.

- Information sharing is significant to successful inter-organizational cooperation.

- A longitudinal perspective should be considered; experience from past critical situations affects current crisis response and reactions. 
In addition, cultural and societal settings (e.g., values, attitudes and demographics) that strongly influence the preparation for and the reaction to critical events with regard to victims and first responders in specific environments were taken into account.

\section{System Dynamics Methodology}

The CRISADMIN Project employs a computer simulation modeling methodology based on systems dynamics and feedback for studying and managing complex issues and problems encountered during crisis events. The feedback systems, such as social response, are defined as a collection of interacting elements working together for a certain purpose. The key element is to consider the concatenation of causal relations through which any component of a system can influence the behavior of other components that may be proximal or distant in terms of the apparent connections [6].

Originally developed in the 1950 s to help corporate managers improve their understanding of industrial processes, system dynamics is currently used to understand the dynamic behavior of complex systems [6]. The application is based on the fact that the structure of any system relies on circular, interlocking and time-delayed relationships among its components.

Sterman [11] stated that the main properties of a system that can be successfully represented using a system dynamics approach are: (i) presence of quantities that vary over time; (ii) variability based on causal dependencies; and (iii) feedback loops containing the main causal influences of a closed system. Additionally, Sterman argued that system dynamics, as a decision modeling approach, is very applicable in contexts where standard analysis is made difficult by the wide range of available data. It is particularly applicable to systems that are highly influenced by soft variables, which are not directly measurable (e.g., trust in first responders, attitudes of the public and panic diffusion).

In recent years, the system dynamics approach has been used to prevent and manage security/defense issues, primarily because it takes into account randomness and interdependencies that characterize behavior in real-world environments. This is made possible by including the soft variables typical of interrelated social systems. The idea behind the system dynamics approach is that if the system structure defines the behavior of the system, then accurately analyzing and determining the interrelationships among the various components of the system produces an accurate understanding of the dynamics of the system [11].

The CRISADMIN Project uses system dynamics to forecast the evolution of the modeled components (i.e., territorial features, timing of the critical event, environmental factors, types of actors involved and social behaviors) from the occurrence of a critical event until the realization of the subsequent impacts. The holistic approach of system dynamics requires that the entire context be considered and that factors perceived as weak or not strictly related be disregarded. This aspect is intended to help avoid defining a model that is difficult to manage and/or interpret. 
Table 1. Example influences among the identified variables.

\begin{tabular}{|c|c|c|}
\hline Influencing Parameter & Influenced Parameter & Notes \\
\hline Crest (Flood) & $(+)$ Inundation area & $\begin{array}{l}\text { Calculated using } \\
\text { elevation map }\end{array}$ \\
\hline Total Inundation Area & $(+)$ Involved structures & $\begin{array}{l}\text { Ascertained by } \\
\text { first responders }\end{array}$ \\
\hline $\begin{array}{l}\text { Energy Production } \\
\text { Damage }\end{array}$ & $(-)$ Electricity disruption & $\begin{array}{l}\text { Adjustment of } \\
\text { rate on lost power }\end{array}$ \\
\hline $\begin{array}{l}\text { Electricity Station } \\
\text { Damage }\end{array}$ & (-) Electricity disruption & $\begin{array}{l}\text { Adjustment of } \\
\text { rate on lost power }\end{array}$ \\
\hline
\end{tabular}

The identification of relevant influences within the system dynamics framework makes it possible to understand the connections among critical infrastructures and to model the impacts of critical events, taking into account the dynamics of an infrastructure as a function of the operations of other critical infrastructures that are not affected directly. System dynamics simulations must represent the main mutual influences of the parameters identified in the theoretical model, defining each influence as positive (i.e., reinforcing) or negative (i.e., dampening), and the related value and timing. Table 1 presents example influences among the identified variables.

The overall model uses interactions among influences and additional information to estimate the total direct and indirect impacts arising from a critical event. This approach allows for the comparison of impacts within the socioeconomic context that is represented as a dynamic system. Once they are consolidated, the proposed influences are tested using data gathered from relevant case studies.

\section{Data Collection}

In order to apply the CRISADMIN approach, four critical events related to previous terrorist attacks and floods were identified and analyzed. The following criteria drove the selection of the events:

- Threat Likelihood: The frequency of terrorist attacks has increased since the events of September 11, 2001, reinforcing the view that a terrorist attack is a real possibility [4]. Floods are also becoming more frequent.

- Historical Event Frequency: Special attention is placed on terrorist attacks in Spain and the United Kingdom - countries that have suffered from ethnic terrorism for decades, from the Euskadi Ta Askatasuna (ETA) and the Irish Republican Army (IRA), respectively, and, more recently, have had to deal with attacks by Islamic terrorist groups. Meanwhile, Europe has seen increased flooding incidents; examples are the 2002 Glasgow 
flood in the United Kingdom, the 2001 Po river floods in Italy and the 2011 Genoa flood in Italy.

- Critical Infrastructure Impact: Terrorist attacks and floods destroy essential assets, and impact critical infrastructures directly or indirectly. These events tend to have major impacts on the transportation, energy and telecommunications sectors.

Four case studies were used to apply and validate the CRISADMIN approach. The case studies include: (i) Madrid bombings of 2004; (ii) London bombings of 2005; (iii) Central and Eastern Europe floods of 2002; and (iv) United Kingdom floods of 2007. The following sections briefly describe the selected case studies and highlight their essential elements and impacts.

\subsection{Madrid Bombings (2004)}

On the morning of March 11, 2004, explosive devices were detonated aboard four commuter trains in Madrid [10]. The affected trains were traveling on the same line and in the same direction between the Alcala de Henares and Atocha stations. A total of thirteen improvised explosive devices were placed on the trains. Ten of the devices exploded; two of the remaining three devices were detonated by Spanish Police bomb disposal experts at the Atocha and El Pozo stations. The thirteenth bomb was not found until later in the evening, having been stored inadvertently with luggage taken from one of the trains. In the following days, official investigations made by the Spanish Judiciary determined that the attacks were directed by a Muslim terrorist cell, which was inspired by al-Qaeda, although no direct al-Qaeda participation was ever established [8].

The terrorists boarded the four commuter trains, each with a capacity of 6,000 passengers. They hid thirteen bomb bags (backpacks) amongst passenger luggage in several carriages before disembarking. Each backpack contained approximately ten kilograms of dynamite; some of the bags were filled with nails and other shrapnel to cause serious wounds to commuters. The explosive devices, which were activated by mobile phone alarms, were set to explode at various commuter stations to maximize casualties and property damage.

The bombings killed 177 people instantly and wounded approximately 1,858 others. Fourteen of the injured people subsequently died, bringing the final death toll to 191. More than 550 staff members and 100 vehicles from SAMUR Civil Protection were involved in the rescue and management activities. Within 90 minutes, SAMUR mobilized more than 325 people, increasing their staffing from 75 to 400 people, and recalled 70 vehicles. Healthcare-related activities in the emergency areas were performed by SAMUR and other local institutions.

The transportation sector was the only one to be directly affected by the bombings, in particular the four trains and the stations where the explosions occurred. The four trains were on the same track, heading towards Atocha Station (main commuting point in Madrid), El Pozo Station, Santa Eugenia Station and Calle Tellez Station. The energy and telecommunications infra- 
structures were not directly targeted by the bombing attacks. However, the telecommunications infrastructure experienced massive overloads due to general panic and crisis management needs.

\subsection{London Bombings (2005)}

On July 7, 2005, three London subway stations (Aldgate, Edgware Road and Russel Square) were attacked by suicide bombers. In addition, a bomb was placed in a double-decker bus that detonated in Travistock Square [7]. The bombings were carried out by four Islamic extremists, who were angered by Britain's involvement in the Iraq War. At about 8:50 A.M., three almost simultaneous explosions detonated in the tunnel between Liverpool Street and Aldgate stations, on the line at Edgware Road and in a Piccadilly Line tunnel between King's Cross and Russell Square.

Almost an hour later, at 9:47 A.M., the bomb placed in the double-decker bus was detonated at Travistock Square. The location of the bomb inside the bus resulted in the front of the vehicle remaining mostly intact. Indeed, most of the passengers in the front of the top deck survived, as did those near the front of the lower deck, including the driver. Individuals at the top and lower rear of the bus suffered more serious injuries. Several passersby were injured by the explosion and some surrounding buildings were damaged by debris. In order to ensure the maintenance of normal security and civil protection services in the city, the choice was made to send only critical staff to the bombing sites - leaving non-essential personnel, equipment and materials at headquarters in the stand-by state. Only the transportation infrastructure was directly affected by the bomb blasts.

\subsection{Central and Eastern Europe Floods (2002)}

In August 2002, severe flooding affected portions of Austria, the Czech Republic and Germany [13]. Heavy rainfall from storms that crossed central Europe during early August triggered sequential flood waves along two major river systems. The flood waves moved down the Danube through Austria and down the Vltava and Elbe rivers in the Czech Republic and Germany. The flooding event covered a period of approximately fourteen days from August 6 until August 20,2002. The event included precipitation as well as flash floods along the involved rivers in Central and Eastern Europe.

The August 2002 floods were due to two major factors: unusual meteorological conditions and human activities (e.g., housing construction, land drainage and deforestation). The flood event was triggered by unusual meteorological conditions, which included two periods of intense rainfall during the first half of August 2002. As usual, the water temperatures in the Adriatic and Mediterranean were significantly higher in August than in the spring, causing substantial amounts of atmospheric moisture that fueled the extreme rainfall. The first period of rain on August 6 and 7, 2002 fell in the southwestern Czech Republic and northeastern Austria, immediately north of a weak area of low 
pressure. Rainfall accumulations were generally less than $125 \mathrm{~mm}$ over the two-day period, but intense rainfall of up to $255 \mathrm{~mm}$ was observed in some locations.

The rainfall triggered flood waves in the upper portions of the Danube and Vltava catchment areas. One flood wave progressed down the Danube through Austria, Slovakia and Hungary, causing minor damage. A more critical flood wave progressed down the Vltava through Prague and down the Elbe through northern Bohemia and Germany. Upon reaching Germany, the flood waters in the Elbe inundated Dresden, causing damage to residential and commercial property as well as many historical buildings in the city center. The increase in river height in Dresden was more gradual and of greater magnitude than the flood peak in Prague. Although Prague itself was hardly hit by the flash flood, damage occurred in the historical and residential parts of the city center.

The greatest number of fatalities (58) was caused by floods resulting from the first wave on the eastern coast of the Black Sea. Seventeen people died in the Czech Republic, 21 in Dresden and more than 100 fatalities were reported across Europe. Direct and indirect impacts on the transportation and energy infrastructures were registered.

\subsection{United Kingdom Floods (2007)}

In June and July 2007, the United Kingdom was stricken by a series of severe floods arising from heavy rainfall during an unseasonably wet weather pattern [2]. The severe flooding events were attributed to two major causes: (i) position of the Polar Front Jet Stream; and (ii) high North Atlantic sea surface temperatures.

Heavy rainfall is not unusual in the United Kingdom during the summer months, but the frequency and spatial extent of the rainfall in June and July 2007 were unprecedented. Exceptional rainfall events occurred on June 25 and July 20, which caused widespread floods across England. The floods ranged from small, localized flash floods to widespread events affecting major river basins. First, northeastern England was badly affected by severe rainfall events in June, which caused floods in Sheffield, Doncaster, Rotherham, Louth and Kingston-upon-Hull. Some areas were hit again by further flooding after severe rain in July that affected a much larger area of central England, including Oxford, Gloucester, Tewkesbury, Evesham and Abingdon. The intense rainfall saturated the catchment areas, resulting in rivers flooding their banks in several major river basins. Disruptions to power and water supplies during the July floods were caused by flooding at the Castlemeads power substation near Gloucester and at the Mythe water treatment plant in Tewkesbury.

A total of thirteen people died as a result of the floods and approximately 48,000 homes were damaged. The scale and speed of the floods came as a shock. Although most people were aware of the impending heavy rain that was forecasted, they did not anticipate the magnitude of the rainfall. Indeed, most people involved in the incident had never experienced such flooding and did not 
know how to react. At the peak of the flooding, around 350,000 homes across Gloucestershire were left without water and 50,000 homes without power.

\section{CRISADMIN Prototype}

The CRISADMIN Project seeks to demonstrate, by means of a prototype, that a flexible system dynamics modeling engine can assist first responders and decision makers in managing critical events. During actual events, knowledge of the past, coupled with the current aspects of a given context, form the basis for selecting modeling parameters and defining influences.

The CRISADMIN decision support system takes into account experience gained through participation in projects associated with the design of modeling methods and tools for monitoring and contrasting emergencies [1]. The decision support system incorporates a three-tiered architecture: (i) a back-end that stores variables and parameters associated with the four domains; (ii) a core that houses the system dynamics modeling engine; and (iii) a front-end that maintains the parameters, activates the functions and presents results.

The simulation model will be made available to institutions and organizations across the European Union - public entities (e.g., civil protection and fire brigades) as well as private entities (e.g., infrastructure asset owners and operators). Crisis management is typically performed in interconnected operations control rooms (OCRs) that continuously monitor critical events. The CRISADMIN decision support system is designed for use by analysts in OCRs as they coordinate activities during critical events. The decision support tool will be used to support operational decisions that benefit from the continuous monitoring capabilities provided by OCRs. The tool will provide decision makers with a starting point that is both expandable and customizable. The tool environment will also engage several fixed and non-customizable scenarios and situations that encompass different crisis situations. This feature will enable decision makers to understand the dynamics of interacting critical infrastructure assets. The prototype will also provide decision makers with points of reference as they select appropriate policy alternatives for crisis management.

\section{Conclusions}

Decision makers responsible for infrastructure protection and crisis management must understand the consequences of policy and investment options before they enact solutions. This notion is particularly important due to the highly complex alternatives that must be considered when protecting critical infrastructures in the current threat environment. An effective way to examine and pursue trade-offs involving risk reduction and protection investments is to utilize a decision support system that incorporates information about threats and the consequences of disruptions. System dynamics modeling, simulation and analysis can be used to conduct impact assessments and risk analyses based on realistic scenarios. 
The system dynamics approach developed under the CRISADMIN Project provides decision makers with a methodology for understanding and evaluating potential risks. The approach can be readily applied in contexts where standard analysis is made difficult by the wide range of available data and/or relationships. The approach is especially suited to systems that are greatly influenced by the "soft" variables associated with human behavior.

The CRISADMIN effort has identified the main parameters associated with the dependencies that impact the evolution of critical events. The result is a simple, yet effective, representation of how an event influences the behavior of a larger interconnected system. As new threats from terrorism and environmental factors emerge, a tool that enables decision makers to anticipate the impacts of critical events would provide them with precious insights for crafting protection strategies and implementing response actions.

\section{Acknowledgements}

This research, conducted by personnel from the Department of Computer, Control and Management Engineering of La Sapienza University, FORMIT Foundation, Erasmus University Rotterdam, Theorematica and Euro Works Consulting, was performed under the CRISADMIN Project. The CRISADMIN Project is supported by the Prevention, Preparedness and Consequence Management of Terrorism and Other Security-Related Risks Program launched by the Directorate-General of Home Affairs of the European Commission.

\section{References}

[1] P. Assogna, G. Bertocchi, A. Di Carlo, F. Milicchio, A. Paoluzzi, G. Scorzelli, M. Vicentino and R. Zollo, Critical infrastructures as complex systems: A multi-level protection architecture, Proceedings of the Third International Workshop on Critical Information Infrastructure Security, pp. 368-375, 2008.

[2] BBC News, The summer floods: What happened (news.bbc.co.uk/2/hi/ uk_news/7446721.stm), June 25, 2008.

[3] L. Bourque, K. Shoaf and L. Nguyen, Survey research, International Journal of Mass Emergencies and Disasters, vol. 15(1), pp. 71-101, 1997.

[4] W. Enders and T. Sandler, The Political Economy of Terrorism, Cambridge University Press, Cambridge, United Kingdom, 2012.

[5] European Commission, Identification and Designation of European Critical Infrastructures and the Assessment of the Need to Improve Their Protection, Council Directive 2008/114/EC, Brussels, Belgium, December 8, 2008 .

[6] S. Friedman, Learning to make more effective decisions: Changing beliefs as a prelude to action, The Learning Organization, vol. 11(2), pp. 110-128, 2004. 
[7] London Assembly, 7 July Review Committee, Volume 4: Follow-Up Report, London, United Kingdom (legacy.london.gov.uk/assembly/reports/ 7 july/follow-up-report.pdf), 2007.

[8] E. Nash, Madrid bombers "were inspired by Bin Laden address," The Independent (www.independent.co.uk/news/world/europe/madrid-bomb ers-were-inspired-by-bin-laden-address-423266.html), November $7,2006$.

[9] W. Orlikowski and S. Scott, Sociomateriality: Challenging the separation of technology, work and organization, The Academy of Management Annals, vol. 2(1), pp. 433-474, 2008.

[10] E. Owen, Bomb squad link in Spanish blasts, The Times Online (www.timesonline.co.uk/tol/news/world/article447363.ece), June 19, 2004.

[11] J. Sterman, Business Dynamics: Systems Thinking and Modeling for a Complex World, McGraw-Hill/Irwin, Columbus, Ohio, 2000.

[12] R. Thurlby and K. Warren, Understanding and managing the threat of disruptive events to the critical national infrastructure, Proceedings of the Asset Management Conference, pp. 1-10, 2012.

[13] U. Ulbrich, T. Brucher, A. Fink, G. Leckebusch, A. Kruger and J. Pinto, The Central European floods of August 2002: Part 1 - Rainfall periods and flood development, Weather, vol. 58(10), pp. 371-377, 2003. 